\title{
SARCOIDOSIS*
}

\section{SWELLINGS ON THE NOSE AND LATE OCULAR SEQUELAE}

\author{
BY
}

\author{
P. A. JOHNSON \\ Durban, South Africa
}

THIS case is described, not because of the rarity of systemic sarcoidosis, but to record the long interval before the onset of intra-ocular complications, and the unusual nature of the presenting symptoms, namely puffy eyelids and symmetrical nodules on the nose.

\section{Case Report}

An Indian male aged 28 years complained of itching and swelling of the upper lids on September 4, 1957.

Examination.-There was a mild conjunctival injection and some oedema of the upper lids. No intra-ocular disease was found.

A small nodule resembling a sebaceous cyst was noted on the left side of the forehead underlying a small linear scar from an old injury.

After 10 days the nodule on the forehead had increased in size, the eyelids were still puffy, and swellings which were hard, painless, and fairly well defined in the form of pads, about the size and shape of an almond, had developed on each side of the bony part of the nose. These swellings were movable and not attached to skin or bone (Figure).

Laboratory Investigations. - A patch test for tuberculosis was negative. The blood count showed $\mathrm{Hb} 15.6 \mathrm{~g}$. per cent $=106$ per cent; erythrocyte sedimentation rate 12 $\mathrm{mm}$./hr; white blood cells 7,000; circulating eosinophils 250. Chest $x$-ray: "Nodular shadowing throughout both lung fields, suggestive of tuberculosis, but sarcoid cannot be excluded"; hand $x$-ray: "N.A.D." The sputum and urine were negative. Biopsy of nodule on nose: "Strands of collagen bundles with intervening myxomatous tissue; diagnosis not possible from these sections". Biopsy of nodule on forehead: "Definite sarcoidosis".

Progress.-After 5 weeks the patient still felt perfectly well with no respiratory symptoms, but he had developed ill-defined puffy swellings on both forearms and complained of slight pain in the wrists on clenching the fists.

After 8 weeks the swellings were subsiding and he returned to work.

After 11 weeks he again reported for examination and was feeling perfectly well. The swellings were almost gone and the eyes were giving no trouble. There was a slight ciliary flush and a few large mutton-fat keratic precipitates in both eyes. This was the first time any ocular complications had been found. 


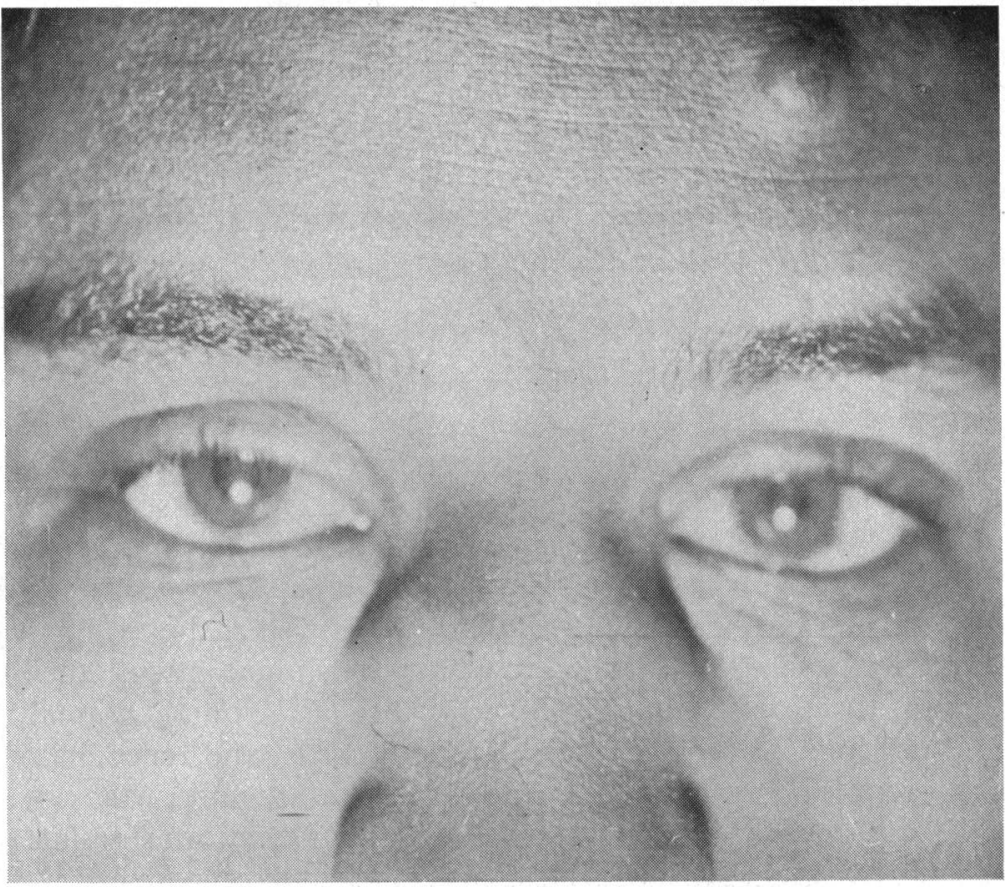

FIGURE.-Sarcoid nodules on nose and forehead.

Treatment had mainly taken the form of placebos. Steroid therapy was not used.

My thanks are due to Dr. T. Edmunds, Senior Ophthalmologist, and to the Superintendent, King Edward VIII Hospital, Durban, for permission to publish this case. 